\title{
Editorial: Expansion of the Wireless Personal Communication International Journal
}

\author{
Ramjee Prasad
}

Published online: 2 March 2011

(C) Springer Science+Business Media, LLC. 2011

It is my great pleasure to announce from January 2011, the expansion of the Wireless Personal Communications International Journal. As the founding and current Editor-in-Chief of the Wireless Personal Communications International Journal since 1994, I am delighted to see the Journal grow to a level of worldwide renowned publication and reference source with a continuous number of paper submissions.

Due to the many submissions and requests, as of our first January Issue in 2011, the Journal is getting expanded to twelve regular issues and twelve Special issues per year. This is a big jump from the original four issues per year, with which the journal started back in 1994. The reasoning behind this expansion is to make the Wireless Personal Communications Journal a platform for cutting-edge publications of top research results by speeding up the process from submission to final printed publication.

The aims and scope of the journal remain the same, to be a strong pillar of dissemination of top research results and innovations in the area of wireless personal communications with basic and emerging enabling technology areas such as, but not limited to:

- pervasive telecommunications

- networking and architectures

- resource and mobility management

- autonomic communications

- cognitive radio

- $\quad$ spectrum management strategies, including policies

- ad hoc networks

- intelligent devices

- multiple access techniques

- intelligent transportation systems

R. Prasad $(\bowtie)$

Center for TeleInFrastruktur (CTIF), Global ICT Standardisation Forum for India (GISFI),

Aalborg University, Niels Jernes Vej 12, 9220 Aalborg Øst, Denmark

e-mail: prasad@es.aau.dk

Url: http://ctif.aau.dk/

Url: http://gisfi.org 
- channel modeling and propagation

- sensor networks and technologies

- security, privacy and trust

- wireless robotics

- energy-efficient communications

- satellite and navigation technologies

- ICT application areas (e.g., telehealth, e-governance)

- standardisation and regulatory issues

The key technology and strategy of the journal will essentially remain the same, with raising the level of the reviewing process, which is targeting the publication of featured articles of the highest quality. Our goal is to become the strongest and most renowned scientific research journal in the area of wireless communications.

\section{Author Biography}

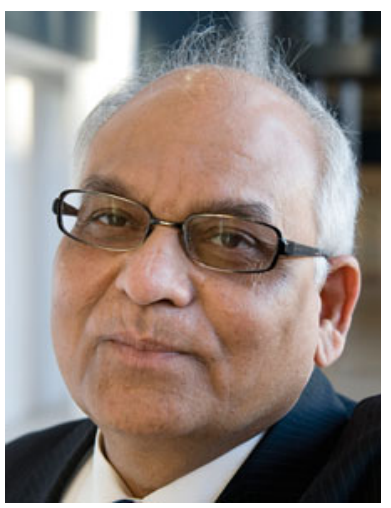

Ramjee Prasad is a distinguished educator and researcher with a long path of experience through achievements until to date in the academic research of the wireless and mobile communication area that have paved the road from first generation telecommunication systems towards the current next generation. Ramjee Prasad has an outstanding technical leadership, managerial and business skills that have led to the globalization of mobile and wireless research and education and their elevation to a new level through an effort towards commercialisation of research results. He is a worldwide established scientist which is visible from his many international academic, industrial and governmental awards and distinctions, huge number of books (more than 30), journal and conferences publications (more than 700), a sizeable amount of graduated Ph.D. students (more than 60) and even larger amount of graduated M.Sc. students. Ramjee Prasad is currently the Director of the Center for TeleInfrastruktur (CTIF) at Aalborg University, Denmark and Professor, Wireless Information Multimedia Communication Chair. Ramjee Prasad is the Founding Chairman of the HERMES Partnership (http://www.hermes-europe. net) a network of leading independent European research centres established in 1996, of which he is now the Honorary Chair. He is the Founding Chairman of the Global ICT Standardisation Forum for India (GISFI: http://www.gisfi.org) established in 2009. Ramjee Prasad is the founding editor-in-chief of the Springer International Journal on Wireless Personal Communications. He is a member of the editorial board of other renowned international journals and is the series editor of the Artech House Universal Personal Communications Series. Ramjee Prasad is a member of the Steering, Advisory, and Technical Program committees of many renowned annual international conferences (e.g., Wireless Personal Multimedia Communications Symposium (WPMC); Wireless VITAE, etc). Ramjee Prasad is a Fellow of the Institute of Electrical and Electronic Engineers (IEEE), USA, the Institution of Electronics and Telecommunications Engineers (IETE), India; the Institution of Engineering and Technology (IET), UK; and a member of the Netherlands Electronics and Radio Society (NERG), and the Danish Engineering Society (IDA). 